\title{
Sindicalização e identidade política dos jornalistas brasileiros
}

\author{
Samuel Pantoja lima \\ Universidade de Brasília (UnB) - E-mail: samuca13@gmail.com \\ Graduado em Jornalismo pela UFSC (1998), é mestre (1999) e doutor (2005) \\ em Mídia e Teoria do Conhecimento pela mesma instituição. \\ Docente da Faculdade de Comunicação e professor visitante na UFSC desde 2010.
}

JACQUES MICK

Universidade Federal de Santa Catarina (UFSC) - E-mail: jacques.mick@ufsc.br Professor do Departamento de Sociologia e Ciência Política e do Programa de Pós-Graduação em Sociologia Política da UFSC. Graduado em Jornalismo (1992), com mestrado (1999) e doutorado (2004) em Sociologia Política pela UFSC. Coordenou a pesquisa "Perfil profissional do jornalismo brasileiro".

\section{Resumo}

O artigo estuda as razões da baixa taxa de sindicalização dos jornalistas brasileiros - de 25,2\% em 2012, conforme recente pesquisa de perfil da categoria (MICK; LIMA, 2013), índice inferior à metade da taxa de sindicalização dos trabalhadores urbanos do Brasil. Para identificar possíveis causas do fenômeno, o artigo compara as características demográficas, políticas e de trabalho dos sindicalizados e dos não sindicalizados. Na análise, consideram-se especialmente as variações por faixa etária, a diversificação do trabalho, as dimensões das equipes e as opções políticas dos dois grupos, como filiação partidária, autoidentificação ideológica e atuação em associações e entidades da sociedade civil. Os dados permitem produzir hipóteses relativas às dificuldades que dirigentes sindicais encontrarão se desejarem expandir a sindicalização na categoria.

Palavras-chave: Jornalismo; perfil profissional; sindicalização.

\section{ABSTRACT}

The article studies reasons for low rates of unionization among brazilian journalists - 25,2\% -, as shown in a recent research concerning the category's professional profile (MICK; LIMA, 2013), an index lower than half of the unionization's rate among urban workers in Brazil. In order to identify possible causes to this phenomenon, the article compares the political and demographic characteristics of both unionized and non-unionized workers. Especially taken in account in the analysis of both groups are the diversification of labor, team size and political inclinations such as political affiliation, ideological selfidentification and protagonism in civil society associations and other entities. The data allows the production of hypotheses regarding the difficulties that union rulers will have if they desire to increase the unionization in the category.

Keywords: Journalism; professional profile; unionization.

Artigo recebido em 05/06/2013

Aprovado em 30/06/2013

1 Versão preliminar deste texto foi apresentada por Samuel Lima no II Colóquio Internacional Mudanças Estruturais no Jornalismo (MEJOR 2013), em maio de 2013, em Natal (RN). Este artigo foi significativamente ampliado. 


\section{Introdução e Metodologia}

Apenas 25,2\% dos jornalistas brasileiros são filiados a sindicatos; deles, 90,2\% são sócios de algum dos 31 sindicatos de jornalistas profissionais do país. Os dados são de pesquisa de perfil da categoria realizada em 2012 com 2.731 jornalistas de todas as unidades da federação e também do exterior (MICK; LIMA, 2013). ${ }^{2}$ Além de informações demográficas e relativas ao trabalho, o levantamento colheu dados sobre características políticas dos jornalistas brasileiros, destacando-se a sindicalização, a filiação partidária, a atuação em organizações sociais e as opiniões quanto a exigência de formação superior específica para o exercício da profisssão e a criação de órgão de autorregulamentação.

Neste artigo, pretendemos identificar possíveis causas para a taxa sindicalização relativamente baixa da categoria - inferior à metade do percentual nacional de sindicalizados entre trabalhadores urbanos, de 59,57\% em 2009 (IBGE, 2001-2009). As hipóteses explicativas serão produzidas a partir da análise de aspectos selecionados da base de dados da pesquisa de perfil, comparando diferenças demográficas, políticas e do trabalho entre profissionais sindicalizados e não sindicalizados.

Os dados foram obtidos através de uma enquete em rede, de participação espontânea, feita predominantemente pela internet entre 25 de setembro e 18 de novembro de $2012 .{ }^{3}$ O questionário foi concebido colaborativamente pela equipe de

2 A pesquisa foi realizada em parceria com a Federação Nacional dos Jornalistas (Fenaj) e contou com o apoio decisivo da Associação Brasileira de Pesquisadores em Jornalismo (SBPJor) e do Fórum Nacional de Professores de Jornalismo (FNPJ). Foram colhidas respostas de 5 mil participantes, reorganizadas num plano amostral com 2.731 respondentes, cujo parâmetro foi a distribuição regional dos registros de jornalista profissional emitidos pelo Ministério do Trabalho e Emprego (MTE) entre 1980 e 2011. Nenhuma das pesquisas com jornalistas em 31 países e territórios publicadas por Weaver; Villnat (2012) teve amostragem numericamente tão expressiva. Apenas na Dinamarca e na Suíça logrou-se obter amostras com mais de 2 mil jornalistas (2008 e 2020, respectivamente) e em oito países os pesquisadores conseguiram respostas de mais de mil profissionais. O levantamento censitário coordenado por Rebelo (2011) em Portugal é uma notável exceção, num cenário de pesquisas em geral caracterizadas por amostragens de pequeno porte.

3 A técnica é denominada, na bibliografia internacional, online survey ou web survey. A pesquisa foi divulgada por amplo conjunto de instrumentos: notícias em veículos de circulação dirigida a 
pesquisa (10 bolsistas de graduação, três mestrandos, dois doutorandos e três professores coordenadores). Foram tomados como referência inúmeros estudos de perfil realizados anteriormente no Brasil e em outros países ${ }^{4}$. As perguntas foram agrupadas em blocos temáticos, destinados a obter informações sobre características demográficas e políticas, características gerais do trabalho e específicas dos profissionais em cada um dos três segmentos principais da categoria: os trabalhadores em mídia, os trabalhadores fora da mídia e os docentes ${ }^{5}$.

Na primeira seção, comparam-se características demográficas selecionadas de sindicalizados e não sindicalizados, explorando-se a possibilidade de que fatores geracionais incidem sobre a decisão de filiar-se ou não a órgão de classe. Na segunda seção, comparam-se dados relativos ao trabalho, para observar obstáculos à sindicalização no tipo de atividade, na intensidade da jornada ou no porte das empresas. $\mathrm{Na}$ terceira, comparam-se indicadores de caráter político-ideológico. Nas considerações finais, relacionam-se as hipóteses explicativas desenvolvidas nas seções anteriores às justificativas apresentadas pelos jornalistas para a não sindicalização.

Os dados da pesquisa refletem a recente expansão da oferta de ensino superior de jornalismo no país. Nos últimos 20 anos, efeitos das transformações estruturais do capitalismo, da redemocratização do país e das mudanças na regulamentação do ofício

jornalistas; e-mails distribuídos aos profissionais pelos 31 sindicatos filiados à Fenaj; mensagens remetidas aos coordenadores dos 317 cursos de jornalismo do país; notas nos boletins das três entidades que apoiaram o levantamento; postagens em redes sociais compartilhadas por profissionais de todo o país. Cada participante foi estimulado a multiplicar, em sua rede de contatos, o convite para participação na pesquisa. A metodologia é descrita em detalhes em Mick (2013).

4 Tais como os de Herscovitz (2000; 2010) e Rebelo (2011).

5 Foram obtidas desse modo 5.000 respostas espontâneas, em todas as unidades da federação e no exterior. A base bruta de dados foi saneada na primeira quinzena de novembro. Restaram 4.183 respostas de consistência aceitável. A esse estoque, foram acrescentadas as respostas de 33 jornalistas do estado de São Paulo, colhidas por telefone em levantamento paralelo focado em profissionais com registro, conduzido pela equipe de pesquisa. (Esse levantamento foi interrompido, sem ter sido concluído, em função das imensas dificuldades de localizar por telefone ou e-mail uma ampla amostra intencional de jornalistas sorteados em relações de detentores de registro obtidas junto ao Ministério do Trabalho e do Emprego). 
reconfiguraram significativamente as possibilidades de atuação profissional dos jornalistas, alterando-se competências e habilidades deles demandadas. A política de expansão do ensino superior, sem responder diretamente a tais fatores, combinou-se a eles como fator chave para a expansão exponencial da categoria e a diversificação das áreas de atuação dos profissionais. ${ }^{6}$ A categoria tornou-se, assim, predominantemente jovem, feminina, com ensino superior completo e baixas taxas de participação política em especial, para o que interessa a este texto, a sindicalização.

\section{Fatores demográficos incidem sobre a sindicalização?}

Ao final de 2012, os jornalistas brasileiros eram majoritariamente mulheres brancas, solteiras, com até 30 anos, praticantes de alguma religião, com ensino superior completo. Do ponto de vista do gênero, 64\% são mulheres e 36\% homens. Considerando cor/raça, o percentual de negros entre os jornalistas era inferior à metade da presença de pretos e pardos no Brasil: $72 \%$ de brancos, contra 23\% de pardos/pretos. Nove em cada dez eram diplomados em Jornalismo, majoritariamente em instituições de ensino privadas, e quatro em cada dez já tinham cursos de pós-graduação. O debate sobre a exigência de formação superior para o exercício da profissão ganha um elemento relevante, quando se considera que $98 \%$ dos jornalistas têm formação superior, destacando-se 91,7\% com formação específica em jornalismo. Os egressos de escolas privadas são amplamente majoritários $(61,2 \%)$, o que reflete o quadro de ofertas de cursos superiores no mercado. Ressalte-se, por fim, que $40,4 \%$ dos jornalistas têm curso de pós-graduação. ${ }^{7}$

6 No período, o número de escolas de jornalismo cresceu continuamente: de 61, em 1990, para 317 vinte anos depois, em 2011. Com potencial para formar a cada ano dezenas de milhares de novos jornalistas (com ou sem registro profissional), tal rede de instituições atua de modo reticular, e seus efeitos sobre o mercado de trabalho escapam à capacidade de observação dos sindicatos da categoria e ao alcance da fiscalização do MTE.

7 Pesquisas coordenadas por Garcia constataram tendências semelhantes em Portugal. "A feminização, o rejuvenescimento, o aumento da formação escolar, o surgimento de novas posições e funções, a estratificação interna e o aumento das disparidades" foram apontados pelo autor como as principais 
No que se refere a gênero e a cor/raça, não há diferenças significativas entre os grupos de sindicalizados e de não-sindicalizados. A parcela de homens entre os sindicalizados é um pouco maior que a média da categoria: são $58,6 \%$ as mulheres e $41,4 \%$ os homens nesse segmento. O grupo de não sindicalizados converge com o perfil geral da profissão: 65,5\% feminino e 34,5\% masculino. Quando se fala de cor/raça, a convergência com o perfil geral afeta ambos os grupos: $73,2 \%$ dos não sindicalizados são brancos $(23,2 \%$ de pardos e pretos); $69,5 \%$ dos sindicalizados se declararam brancos $(25,5 \%$ negros e pardos $){ }^{8}$

É na faixa etária que diferenciações dentro da categoria quanto à sindicalização começam a se evidenciar (Tabela 1). A categoria é mais jovem entre os não sindicalizados dos 18 aos 30 anos, com expressivos $67,4 \%$, ou seja mais de dois terços; na mesma faixa etária, os sindicalizados somam pouco mais de um terço - 34,3\%. Nas faixas seguintes (dos 31 aos 50 anos), os sindicalizados totalizam 45,8\% dos profissionais enquanto os não filiados chegam aos $28,7 \%$. Na penúltima faixa, entre 51 e 64 anos, essa diferenciação se acentua: 19\% de sindicalizados, contra apenas 3,8\% de não sindicalizados. Em suma, os sindicalizados concentram-se nas faixas etárias entre 31 e 50 anos, enquanto os não sindicalizados concentram-se dos 18 aos 30 anos. Este é o primeiro indício de que um fator geracional pode estar afetando as taxas de sindicalização da categoria, já que a maior parte dos jornalistas tem menos de 30 anos.

tendências de reconfiguração da categoria no final do século XX (GARCIA, 2009, p. 23).

8 Também não há diferenças entre sindicalizados e não sindicalizados no que se refere à prática de alguma religião. 
Tabela 1 - Jornalistas sindicalizados e não-sindicalizados, por faixa etária (Brasil, 2012)

\begin{tabular}{|l|c|c|}
\hline \multicolumn{1}{|c|}{ Faixa Etária } & Não Sindicalizados & Sindicalizados \\
\hline Entre 18 e 22 anos & $13,5 \%$ & $3,8 \%$ \\
\hline Entre 23 e 30 anos & $53,9 \%$ & $30,5 \%$ \\
\hline Entre 31 e 40 anos & $19,9 \%$ & $27,8 \%$ \\
\hline Entre 41 e 50 anos & $8,8 \%$ & $18 \%$ \\
\hline Entre 51 e 64 anos & $3,8 \%$ & $19 \%$ \\
\hline Mais de 64 anos & $0,2 \%$ & $0,9 \%$ \\
\hline
\end{tabular}

Fonte: Pesquisa "Perfil profissional do jornalismo brasileiro" - PPGSP/UFSC, 2012.

Essa hipótese é reforçada pelos dados relativos ao estado civil nos dois segmentos. Enquanto na média da categoria os solteiros são $60,5 \%$, entre os não sindicalizados esse percentual sobe para $66,8 \%$. Entre os sindicalizados, perfazem $56,8 \%$ os casados, separados, divorciados ou em união estável.

Quanto maior o grau de instrução, maior a tendência à sindicalização (Tabela 2). Os sindicalizados com pós-graduação são 51,5\% (somando-se especialização, mestrado e doutorado), enquanto os não associados nesses níveis de ensino somam 36,2\%. Esse fator está relacionado à distribuição dos segmentos por faixa etária, que se reflete também sobre o tipo de universidade/faculdade cursada pelos profissionais: a presença de não sindicalizados entre os egressos de instituições privadas é maior que a média $(63,3 \%$ contra $60,8 \%){ }^{9}$

9 Não há variação, entre sindicalizados e não sindicalizados, no que se refere à área de formação mesmo porque o predomínio dos cursos de jornalismo é marcante, abarcando $91,7 \%$ dos profissionais com graduação superior. Mas, entre os sindicalizados, o volume dos profissionais que não estão estudando atualmente é significativamente maior que a média da categoria ( $74 \%$ contra $66 \%)$. 
Tabela 2 - Jornalistas sindicalizados e não-sindicalizados, por grau de instrução (Brasil, 2012)

\begin{tabular}{|l|c|c|}
\multicolumn{1}{|c|}{ Grau de Instução } & Não Sindicalizados & Sindicalizados \\
\hline Superior (Bacharelado/Licenciatura) & $61,4 \%$ & $45,1 \%$ \\
\hline Especialização & $26 \%$ & $34,9 \%$ \\
\hline Mestrado & $8,5 \%$ & $12,8 \%$ \\
\hline Doutorado & $1,70 \%$ & $3,8 \%$ \\
\hline
\end{tabular}

Fonte: Pesquisa "Perfil profissional do jornalismo brasileiro" - PPGSP/UFSC, 2012.

A análise da distribuição territorial dos jornalistas na pesquisa indica que os não sindicalizados estão mais concentrados em São Paulo que a média da categoria. Naquele estado encontram-se $36,2 \%$ dos participantes da enquete, mas $40,6 \%$ dos não sindicalizados e apenas $23 \%$ dos sindicalizados. Dada a concentração das atividades de mídia nesse estado, o fator territorial pode apenas refletir efeitos, sobre a sindicalização, das características do trabalho - o que será analisado na próxima seção.

\section{Características do trabalho afetam a sindicalização?}

As competências e habilidades dos jornalistas são, no Brasil, requisitadas por empresas de variados setores; a mídia é o maior deles, mas o percentual da categoria exclusivamente atuante nela é inferior à metade (Tabela 3). A pesquisa de perfil dos jornalistas indica que, nas últimas décadas, a diversificação de atividades jornalísticas clássicas na mídia efetivou-se pela multiplicação de títulos de jornais e revistas, concessões de rádio e TV e veículos de internet, principalmente no setor privado, mas 
também com emergente presença no setor público e no terceiro setor. Fora da mídia, a variedade de possibilidades de atuação profissional comporta, sobretudo, postos no setor público (nos três poderes e nos três níveis de governo) e em empresas privadas de assessoria de imprensa ou comunicação, mas alcança um terço dos jornalistas desse segmento em outras empresas privadas ou organizações do terceiro setor. A atuação na docência envolve $8,4 \%$ dos profissionais da área.

Tabela 3 - Jornalistas por tipo de atividade, conforme as combinações de trabalho jornalístico principal e secundário (Brasil - 2012)

\begin{tabular}{|l|c|}
\hline Tipo de atividade(s) & $\%$ \\
\hline Exclusivamente em mídia, com um ou mais empregos & $45,80 \%$ \\
\hline Exclusivamente fora da mídia, com um ou mais empregos & $33,60 \%$ \\
\hline Com mais de um emprego em mídia e fora da mídia & $12,20 \%$ \\
\hline Profissionais de mídia ou fora da mídia que também atuam como docentes & $4,40 \%$ \\
\hline Exclusivamente docentes & $4,00 \%$ \\
\hline
\end{tabular}

Fonte: Pesquisa "Perfil profissional do jornalismo brasileiro" - PPGSP/UFSC, 2012

Num ou noutro segmento, o trabalho jornalístico é marcado pela polivalência nas atividades. Os jornalistas são de fato profissionais multifuncionais, responsáveis por ações que se distribuem por todo o processo de produção de conteúdos. Assim, por exemplo, embora repórteres fotográficos respondam por apenas 1,7\% das funções na mídia e $0,8 \%$ fora da mídia, $35,4 \%$ e $47,7 \%$ dos profissionais desses segmentos, respectivamente, fotografam como parte das atividades realizadas no trabalho. A concepção de pautas é prática cotidiana de 70,6\% dos jornalistas de mídia e 60,2\% de fora da mídia, apesar de escassas menções à função designada como "pauteiro" ou equivalente. 
Quanto ao porte das empresas, predominam organizações médias na mídia e pequenas fora dela. Na mídia, 35\% trabalham em locais com até quatro jornalistas contratados, $41,5 \%$ em empresas com cinco a 50 jornalistas, enquanto $23,5 \%$ atuam em corporações com mais de 51 jornalistas. Fora da mídia, 73,7\% dos respondentes atuam em locais com até 4 jornalistas contratados; 24,8\% trabalham em organizações de porte médio, com cinco a 50 jornalistas; apenas 1,4\% estão em organizações com mais de 51 jornalistas (MICK; LIMA, 2013).

Tal diversificação constitui evidente dificuldade à organização sindical. A começar, pelo escopo das pautas de reivindicação em cada segmento: na mídia, fora da mídia ou na docência, não apenas há especificidades nas relações de trabalho, como elas variam dentro de cada setor (por exemplo, entre as diversas mídias, entre o setor público e as empresas de assessoria, entre instituições de ensino públicas e privadas). A análise das diferenças entre as características do trabalho dos sindicalizados e não sindicalizados nos três segmentos indica a complexidade inerente à tarefa de representação da categoria.

De partida, chama a atenção o indicador de registros profissionais: apenas 69,2\% dos jornalistas não sindicalizados têm o registro, contra 93,3\% dos filiados às entidades sindicais (a média da categoria é $75,3 \%$ ). A taxa entre os sindicalizados não é surpreendente, porque a maioria dos sindicatos exige o registro como condição para a filiação. Mas, entre os não sindicalizados, a parcela dos profissionais sem registro alcança $30,8 \%$.

Do ponto de vista da área principal de atuação, os números entre os dois grupos em geral convergem, em relação aos dados gerais da pesquisa (segundo a qual, 54,5\% trabalham em mídia, 40,4\% fora da mídia e 5,2\% em docência). Dos não sindicalizados, $55,59 \%$ atuam em mídia, 40,6\% fora da mídia e 3,5\% em docência; dos sindicalizados, $50,6 \%$ estão na mídia, 39,8\% fora da mídia e 9,6\% em docência. Ressaltam-se, portanto, dois indicadores quanto à sindicalização: na mídia, a presença de filiados é inferior à distribuição média dos profissionais por atividade; na docência, a situação é 
inversa, com uma presença quase duas vezes maior de professores entre os sindicalizados em relação à distribuição média da categoria. ${ }^{10}$ Apesar dessas particularidades, contudo, a distribuição dos sindicalizados por tipo de atividade segue as características da profissão, com maior concentração em mídia - o que não descredencia discursos antissindicais baseados numa suposta diferença entre a categoria o conjunto dos filiados.

Um aspecto que indica a precarização do trabalho jornalístico é a questão da jornada diária (Tabela 4). É evidente a convergência de jornada diária, entre os dois grupos, para a faixa entre 5 a 8 horas, considerando que a jornada do jornalista profissional, definida em Lei, é de 5 horas/dia. Há um claro indício de superexploração da carga horária cumprida em funções jornalísticas se aglutinarmos as duas faixas (de 5 até 12 horas/dia), quando se tem: 83,9\% dos não-sindicalizados cumprem essa jornada o que implica em dois ou mais empregos - e entre os sindicalizados esse percentual chega aos $82,9 \%$ dos profissionais. O impacto dessa extenuante jornada, do ponto de vista da saúde no trabalho, é algo a ser mensurado em futuras pesquisas.

Tabela 4 - Jornalistas sindicalizados e não-sindicalizados, por jornada de trabalho em funções jornalísticas (Brasil - 2012, por horas trabalhadas/dia)

\begin{tabular}{|l|c|c|}
\hline \multicolumn{1}{|c|}{ Horas Trabalhadas/Dia (Funções Jornalísticas) } & Não Sindicalizados & Sindicalizados \\
\hline Até 5 horas & $12,1 \%$ & $10,2 \%$ \\
\hline De 5 a 8 horas & $\mathbf{4 2 , 7 \%}$ & $\mathbf{4 4 , 9 \%}$ \\
\hline Entre 8 e 12 horas & $41,2 \%$ & $38,0 \%$ \\
\hline Mais de 12 horas & $4,0 \%$ & $6,9 \%$ \\
\hline
\end{tabular}

Fonte: Pesquisa "Perfil profissional do jornalismo brasileiro" - PPGSP/UFSC, 2012.

$10 \mathrm{O}$ dado refere-se à sindicalização como um todo, comportando, portanto, sindicatos de professores e de outras categorias, além dos de jornalistas. 
Outro indicador relacionado ao fenômeno da precarização do trabalho jornalístico trata do vínculo empregatício. Os dados da Tabela 5 confirmam que o vínculo preponderante ainda é carteira assinada (Carteira de Trabalho e Previdência Social - CTPS), independente do grupo, não obstante o número de contratos de prestação de serviço, freelancer e pessoa jurídica (PJ). Observe-se que, não obstante a prevalência da "carteira assinada", os vínculos precários são bastante expressivos. Somando-se os contratos de freelancer, prestação de serviços e PJs, alcançamos $28,4 \%$ entre os não sindicalizados e $22,1 \%$ dos sindicalizados. No primeiro grupo, um em cada quatro profissionais tem vínculo precário, enquanto entre associados esse número também se aproxima de um quarto dos trabalhadores.

Tabela 5 - Jornalistas sindicalizados e não-sindicalizados, por vínculo empregatício (Brasil - 2012, por horas trabalhadas/dia)

\begin{tabular}{|l|c|c|}
\hline \multicolumn{1}{|c|}{ Vínculo Empregatício } & Não Sindicalizados & Sindicalizados \\
\hline Carteira assinada (CTPS) & $\mathbf{5 8 , 8 \%}$ & $\mathbf{6 2 , 8 \%}$ \\
\hline Freelancer & $12,3 \%$ & $10,7 \%$ \\
\hline Contrato de prestação de serviços & $9,3 \%$ & $4,5 \%$ \\
\hline Pessoa jurídica (PJ) & $6,8 \%$ & $6,9 \%$ \\
\hline
\end{tabular}

Fonte: Pesquisa "Perfil profissional do jornalismo brasileiro" - PPGSP/UFSC, 2012.

Elemento fundamental desse retrato de sindicalizados e não-sindicalizados, entre os trabalhadores de mídia, é o tipo de veículo na qual eles exercem a profissão (Tabela 6). Os dados revelam a predominância da tradicional mídia impressa (em papel) entre os sindicalizados, não obstante o avanço verificado das chamadas mídias digitais. 
Somados, TV e rádio ainda respondem por mais de um terço da mídia entre sindicalizados $(36,6 \%)$ e número similar no grupo de não sindicalizados $(31,8 \%)$. O trabalho na Internet tem indicação bastante expressiva entre não sindicalizados, 46,2\% (contra 40,3\% do outro grupo). A mídia tradicional impressa (jornais e revistas em papel) ainda é responsável pelo maior estoque de empregos na categoria: $61,9 \%$ entre não filiados e $70 \%$ dos filiados aos sindicatos.

Tabela 6 - Jornalistas sindicalizados e não-sindicalizados que trabalham em mídia, por tipo de mídia (Brasil - 2012)*

\begin{tabular}{|l|c|c|}
\hline \multicolumn{1}{|c|}{ Trabalha atualmente em que mídia? } & Não Sindicalizados & Sindicalizados \\
\hline TV & $20,0 \%$ & $25,2 \%$ \\
\hline Rádio & $11,8 \%$ & $11,4 \%$ \\
\hline Internet & $\mathbf{4 6 , 2 \%}$ & $40,3 \%$ \\
\hline Jornal & $39,2 \%$ & $\mathbf{4 9 , 3 \%}$ \\
\hline Revista & $22,7 \%$ & $20,7 \%$ \\
\hline Comunicação interna (intranet e E-mail) & $6,8 \%$ & $7,2 \%$ \\
\hline Agência de notícia & $5,0 \%$ & $8,3 \%$ \\
\hline
\end{tabular}

* A questão era de múltipla escolha.

Fonte: Pesquisa "Perfil profissional do jornalismo brasileiro" - PPGSP/UFSC, 2012.

No caso dos trabalhadores atuando na mídia, destacamos também, no comparativo entre sindicalizados e não sindicalizados, a função: entre ambos os segmentos, prevalece o repórter (48,6\% entre não sindicalizados; $40,3 \%$ entre sindicalizados). Editor alcança $19,2 \%$ do primeiro grupo e $25,5 \%$ do segundo. Isso reforça a impressão de que, entre os jornalistas, a sindicalização está relacionada a maior faixa etária e maior tempo de permanência na categoria. 


\section{Sindicalização e identidade política}

Considerada como indicador elementar do grau de consciência política ou engajamento, a sindicalização reflete o senso corporativo de determinada categoria profissional. A questão se insere num universo de características políticas dos jornalistas, que pode considerar ainda questões como filiação partidária, posicionamento ideológico e atuação em associações e entidades da sociedade civil.

À questão "como você define seu posicionamento ideológico", predomina entre os jornalistas uma posição "à esquerda" (centro-esquerda, esquerda e extrema esquerda), com 49,1\% das respostas; outros 29,9\% optaram por "nenhuma das alternativas"; no somatório entre os que se definiram "à direita" (extrema direita, direita e centro-direita) estão outros $10,4 \%$. Escolheram, por fim, a opção "centro" 7,2\% dos respondentes. Em suma, metade dos jornalistas se considerava de esquerda, mas quase um terço refutava qualquer classificação ideológica.

Os blocos de sindicalizados e não-sindicalizados guardam importantes diferenças em relação a essas médias (Tabela 7). Entre os sindicalizados, prevalece nitidamente a autoidentificação com a esquerda, cuja frequência sobe para 56,6\%. Entre os não-sindicalizados, a faixa de maior concentração é a que recusa qualquer classificação numa matriz esquerda-direita $(31,4 \%)$, as menções a posições de direita são um pouco superiores à média, enquanto as posições à esquerda, um pouco inferiores. 
Tabela 7 - Sindicalizados e não-sindicalizados: Posicionamento ideológico (Brasil - 2012)*

\begin{tabular}{|l|c|c|}
\hline Como você define seu posicionamento ideológico? & Não-Sindicalizados & Sindicalizados \\
\hline Extrema direita & $0,4 \%$ & $0,3 \%$ \\
\hline Direita & $4,7 \%$ & $3,2 \%$ \\
\hline Centro Direita & $6,2 \%$ & $4,2 \%$ \\
\hline Centro & $8,0 \%$ & $5,2 \%$ \\
\hline Centro-esquerda & $22,6 \%$ & $23,0 \%$ \\
\hline Esquerda & $22,8 \%$ & $\mathbf{3 1 , 7 \%}$ \\
\hline Extrema-esquerda & $1,1 \%$ & $1,9 \%$ \\
\hline Nenhuma das Alternativas & $\mathbf{3 1 , 4 \%}$ & $25,9 \%$ \\
\hline
\end{tabular}

Fonte: Pesquisa "Perfil profissional do jornalismo brasileiro" - PPGSP/UFSC, 2012.

Quando a questão se desloca para o campo da filiação partidária, 92,2\% dos jornalistas profissionais brasileiros responderam não serem filiados a nenhum partido político; apenas 7,8\% responderam "sim". É um percentual muito semelhante aos 7,9\% dos brasileiros com filiação a algum dos 29 partidos registrados no país em 2012 (TSE, 2012). Entre os sindicalizados, contudo, o índice de filiados é de quase o dobro em relação à média da categoria: $13,4 \%$. (entre não-sindicalizados, os sem filiação são $6 \%$ ).

Apenas um a cada três jornalistas participava de movimentos sociais, associações ou organizações. Não atuam, mas já atuaram em organizações sociais 19,9\% dos jornalistas; os que nunca atuaram são 45\% dos respondentes. Ou seja, praticamente dois terços dos jornalistas brasileiros não têm nenhum tipo de vínculo ou atuação orgânica nos movimentos sociais. Esse distanciamento está nitidamente associado às baixas taxas de sindicalização e filiação partidária, num círculo que brota da vida sindical restrita, na defesa de melhores salários e condições de trabalho, ao 
exercício mais amplo da cidadania, que se daria num nível partidário ou de outras organizações associativistas. No comparativo entre os dois grupos, entre nãosindicalizados os percentuais somados atingem $67,6 \%$ (48,1\% não atuam e outros 19,5\% não atuam, mas já atuaram), enquanto o percentual geral dos sindicalizados está abaixo da média geral $(59,8 \%)$ e quase $20 \%$ inferior ao grupo de não associados às entidades.

Sindicalizados e não-sindicalizados se distribuem de forma pontualmente distinta face a duas questões políticas chave para a categoria na última década: a exigência de formação superior em jornalismo para o exercício da profissão e a criação de órgão de autorregulamentação profissional. Tanto para sindicalizados, quanto para não sindicalizados, prevalecem os posicionamentos favoráveis, em ambos os tópicos. A maioria dos respondentes $(55,4 \%)$ é a favor da exigência de formação superior específica em Jornalismo, índice que alcança $64,8 \%$ entre os sindicalizados e se mantém em 52,2\% entre os não sindicalizados. Outros $22,8 \%$ entendem ser necessária a formação superior "em qualquer área de conhecimento" (posição de 16,3\% e 25\% de sindicalizados e não sindicalizados, respectivamente), enquanto $12 \%$ dos respondentes são favoráveis à formação específica em jornalismo, em nível de pós-graduação para os não graduados em jornalismo (13,4\% e 11,6\% nos segmentos que estamos examinando neste artigo). Apenas 6,1\% são contra qualquer exigência, índice que sobe para 7,2\% entre os não sindicalizados e cai para $2,8 \%$ dos filiados.

Quanto à criação de um órgão de autorregulamentação, a exemplo de ordens ou conselhos profissionais, notáveis $71,4 \%$ dos respondentes declararam-se "a favor" (76,7\% entre sindicalizados, $69,7 \%$ nos demais), enquanto $13,9 \%$ se posicionaram "contra" (nesse aspecto, não há diferença significativa em relação à média entre os segmentos). São "indiferentes" $7,3 \%$, sendo $5,5 \%$ de sindicalizados e $7,9 \%$ de não sindicalizados. Outros 7,3\% manifestaram "não ter opinião" - 4,8\% entre sindicalizados, $8,1 \%$ nos demais. 


\section{Considerações finais}

Um quarto dos jornalistas brasileiros são sindicalizados e sua distribuição por tipo de atividade representa aproximadamente as características da categoria. Dos profissionais ouvidos pela pesquisa, contudo, $74,8 \%$ responderam não ser sindicalizados. As razões dos que não se filiaram aos sindicatos de jornalistas são diversas. Somente $34,5 \%$ afirmaram "não ter interesse", descartando plenamente a filiação. Outros 43,2\% representam o somatório de respostas que permitem algum nível de intervenção, do ponto de vista das entidades sindicais, a saber: a) diretoria não representa a categoria $(10,6 \%)$; b) não conhece o sindicato $(17,1 \%)$; c) sindicato não responde demandas específicas de sua área de atuação (13,4\%); e d) diretoria dificulta sindicalização $(2,1 \%) .{ }^{11}$ Há, portanto, algum espaço para diálogo e convencimento entre lideranças sindicais e suas respectivas bases, com o objetivo de ampliar a taxa de sindicalização. Contudo, transparecem obstáculos mais profundos, de ordem geracional e ideológica, ou relativos à distribuição dos trabalhores por tipo de atividade, que demandam outro tipo de estratégia de ação sindical.

Um primeiro obstáculo é o fator geracional. Nos jornalistas com até 30 anos encontram-se as principais resistências à sindicalização, inclusive de corte ideológico. Mais de dois terços dos jornalistas não-sindicalizados estão dentro dessa faixa etária: precisamente $67,4 \%$ (13,5\% entre 18 e 22 anos; 53,9\% entre 23 e 30 anos). Como isso coincide com as características etárias da categoria, como evidenciado pela pesquisa de Mick e Lima (2013), constata-se que a nova geração de jornalistas saída das escolas, nos últimos 10 anos, está mais distante das lutas sindicais cotidianas. A sindicalização é mais frequente entre jornalistas que estão há mais tempo na profisssão - mais consolidados na área, portanto -, e têm, em consequência, idade mais elevada.

11 Essa questão suscitou, no campo qualitativo, 378 respostas sobre múltiplas motivações do "não". Desse conjunto, destacam-se quatro subcategorias: a) 42 pessoas reclamaram do custo financeiro da anuidade; b) 12 justificaram que moram no interior dos estados e a entidade sindical não atua lá; c) 7 explicaram que estão desempregadas; por último, d) 4 entrevistados responderam que atuam como PJ (pessoa jurídica) e o sindicato não tem política para esse setor. 
Outro obstáculo parece ser ideológico. Um terço dos respondentes recusa a autoidentificação ideológica numa escala esquerda-direita, no caso dos jornalistas nãosindicalizados aparecendo como o maior percentual isolado $(31,4 \%)$. No caso dos sindicalizados, o maior percentual é de "Esquerda" com 31,7\%. A ponderar que os percentuais somados dos itens "Centro-Esquerda", "Esquerda" e "Extrema-Esquerda" prevalece em ambos os segmentos, entre não-sindicalizados chegando aos 46,5\% e nos sindicalizados bastante acima: $56,6 \%$ dos respondentes.

Um terceiro obstáculo pode estar na diversificação das atividades profissionais dos jornalistas, combinada a sua reticularização em uma miríade de pequenas empresas. $\mathrm{Na}$ mídia, por exemplo, o segmento com maior parcela de sindicalizados é o das grandes empresas, com mais de 51 jornalistas contratados $(23,5 \%$ dos trabalhadores do segmento e $27,6 \%$ dos sindicalizados no setor). Nas faixas de empresas com até quatro jornalistas, a presença de sindicalizados é inferior à distribuição média da categoria. Fora da mídia, contudo, as taxas de sindicalização em relação ao número de jornalistas por empresa são semelhantes à distribuição da categoria, até com variação positiva na faixa de 2 a 4 jornalistas $(38,8 \%$ na média dos jornalistas que trabalham em mídia, $44,3 \%$ dos sindicalizados no segmento). Em todos os casos, a variedade de atividades desenvolvidas por jornalistas afeta a consolidação de identidades profissionais, como ocorre em outros países. ${ }^{12}$

Mais pesquisas são necessárias para explorar as conexões entre esses dados. A heterogeneidade da profissão certamente impõe dificuldades ao trabalho das entidades sindicais, o que provavelmente explica parcialmente as taxas baixas de filiação. É

12 Em relação às condições portuguesas, onde o conceito de "jornalista" designa apenas trabalhadores de mídia, Fidalgo (2004, p. 72) observa: "Tradicionalmente pouco mobilizáveis para reflexões ou aç̧ões colectivas, a não ser em alturas de crise evidente, e reconhecendo-se porventura pouco em alguns dos tradicionais instrumentos de representação (como os sindicatos, excessivamente fixados nas questões de índole laboral e contratual estritas, quando não apegados a visões corporativas que os fecham sobre o seu umbigo), os jornalistas portugueses têm sabido lamentar-se muito, desculpar-se bastante, autoflagelar-se quanto baste, mas pouco mais". A respeito da identidade profissional dos jornalistas, ver também Fidalgo (2009). 
possível também que a composição das direções sindicais mude mais lentamente que a morfologia da categoria: em que medida dirigentes homens e de faixa etária mais alta conseguem identificar, compreender e defender demandas de uma categoria majoritariamente feminina e jovem?

Outras frentes de investigação podem focar as opções políticas dos jornalistas. As taxas de participação em associações ou organizações sociais indicam que os jornalistas brasileiros têm baixo envolvimento comunitário? A deterioração do entendimento do jornalismo como missão está relacionada ou não às taxas de associativismo? Comparações com taxas de associativismo em outras categorias e mais estudos sobre como os jornalistas percebem o sentido de seu próprio trabalho podem ajudar a responder essas perguntas.

O estudo dos obstáculos à ação coletiva dos jornalistas pode levar à compreensão de por que a categoria encontrou tantas dificuldades para conquistar a criação de um órgão de autorregulamentação, como o Conselho Federal de Jornalismo, apesar de a proposta contar com o apoio amplamente majoritário dos profissionais (principais interessados nisso). Também podem ajudar a compreender a situação, aparentemente paradoxal, da categoria em relação ao diploma: embora 89\% dos jornalistas tenham formação superior específica em Jornalismo, apenas 55\% defendem a exigência dessa titulação para o exercício da profissão. ${ }^{13}$

Algumas dessas indagações compõem o escopo de novas etapas da pesquisa Perfil Profissional do Jornalismo Brasileiro, aqui referenciada em seus resultados de 2012. Contudo, fica evidente que a possibilidade de crescimento dos indicadores de filiação às entidades sindicais dos jornalistas dependerá de uma estratégia de dois tipos. De um lado, fatores tipicamente trabalhistas, como localização de bases no interior dos estados, ampliação do contato e interação entre as direções e suas respectivas bases - no caso das novas demandas geradas por alterações mais profundas das condições de

13 Note-se, novamente, que o número de respondentes categoricamente contrários a qualquer exigência de formação superior era de apenas $6,1 \%$. 
trabalho - e a simples divulgação do trabalho dos sindicatos aos seus representados, sindicalizados ou não. No outro espectro, somam-se os obstáculos que aqui caracterizamos como geracionais e/ou ideológicos. Tais fatores devem impor um grau de dificuldade maior à ação dos sindicatos, de forma mais específica às políticas de ampliação das taxas de sindicalização. A resposta dos não-sindicalizados às questões sobre atuação em organizações da sociedade civil, filiação partidária e posicionamento ideológico parecem indicar muito mais que uma divergência pontual, mas um conjunto de crenças e convicções antissindicais da nova geração de jornalistas que está chegando às redações e a outros locais de trabalho. Em sua maioria formado nas instituições de ensino privadas (63\% são egressos desses cursos), jovem (67,4\% dos não-sindicalizados têm até 30 anos) e sem vínculo com qualquer associação e/ou organização da sociedade civil (quase $70 \%$ dos respondentes), esse grupo revela-se particularmente despolitizado. ${ }^{14}$

14 A partir de estudo com jornalistas contatados por meio de redes sociais, Figaro et al. (2011) observaram que "os jovens, não sindicalizados, mantêm vínculos precários, trabalham entre oito e dez horas por dia e em ritmo acelerado. Não planejam a vida fora do curto prazo, vão em busca do cliente e consideram a informação como um negócio. São muito mais preocupados com o negócio, meio de vida, do que com aspirações de mudanças sociais". 


\section{Referências Bibliográficas}

FIDALGO, Joaquim. O jornalista em construção. Porto: Porto Editora, 2009.

FIDALGO, Joaquim. Jornalistas: um perfil socioprofissional em mudança. Comunicação e Sociedade. Vol. 5. Aveiro, 2004, p. 63-74.

FIGARO, Roseli; LIMA, Cláudia do Carmo Nonato; GROHMAN, Rafael. Comunicação no Mundo do Trabalho dos Jornalistas: mudanças no perfil dos profissionais de São Paulo. Artigo apresentado ao $9^{\circ}$. Encontro Nacional de Pesquisadores em Jornalismo. Rio de Janeiro: Universidade Federal do Rio de Janeiro, nov. 2011. Disponível em: http://sbpjor.kamotini.kinghost.net/sbpjor/admjor/arquivos/9encontro/CL 126.pdf. Acesso em: 30 abr. 2013.

FIGARO, R. (coord.) As mudanças no mundo do trabalho dos jornalistas. Grupo de Pesquisa Comunicação e Trabalho CNPq/ECA-USP. São Paulo: Fapesp, 2010. (Relatório de pesquisa). Disponível em http://www.eca.usp.br/comunicacaoetrabalho/wp/index.php/pesquisas/2008-2010/. Acesso em: 01/04/2011.

GARCIA, José Luís (Org.). Estudos sobre os jornalistas portugueses. Metamorfoses e encruzilhadas no limiar do século XXI. Lisboa: Imprensa de Ciências Sociais, 2009.

HERSCOVITZ, Heloiza. Jornalistas brasileiros no século XXI, visões sobre a profissão. Brasília: Fenaj, 2010. Disponível em http://www.fenaj.org.br/arquivos/resultados_enquete_com_jornalistas_brasileiros.doc. Acesso em $05 / 02 / 2011$.

HERSCOVITZ, Heloiza. Jornalistas de São Paulo: quem são e o que pensam em comparação aos jornalistas americanos e franceses. Revista Brasileira de Ciências da Comunicação. Vol. XXIII, n. 2, jul/dez. 2000.

IBGE - Instituto Brasileiro de Geografia e Estatística. Censo Demográfico 2010 Características gerais da população, religião e pessoas com deficiência. Brasília: IBGE, 2010.

IBGE - Instituto Brasileiro de Geografia e Estatística. Pesquisa Nacional por Amostra de Domicílios 2001-2009. Pessoas de 18 anos ou mais de idade ocupadas (per. ref. 365 dias) e associadas a sindicato, por tipo de sindicato. Brasília: IBGE, 2001-2009. Dados disponíveis no IBGE Séries: http://seriesestatisticas.ibge.gov.br/series.aspx? vcodigo $=\mathrm{PD} 313 \& \mathrm{sv}=21 \& \mathrm{t}=$ pessoas-18-anosmais- idade-ocupadas. Acesso em: 06/02/13. 
MICK, Jacques. Detalhamento metodológico da pesquisa "Perfil profissional do jornalismo brasileiro".Florianópolis: TMT/UFSC, 2013. Disponível em: http://perfildojornalista.ufsc.br. Acesso em: 14 fev. 2013.

MICK, Jacques; LIMA, Samuel. Perfil do Jornalista Brasileiro: características demográficas, políticas e do trabalho jornalístico em 2012. Florianópolis: Insular, 2013.

REBELO, José (Coord.) et al.. Ser jornalista em Portugal: perfis sociológicos.

Lisboa/Portugal: Gradiva (2011).

TRIBUNAL SUPERIOR ELEITORAL. Brasil tem 15 milhões de eleitores filiados a partidos políticos. Brasília: TSE, 2012. Disponível em:

http://www.tse.jus.br/noticiastse/2012/Abril/brasil-tem-15-milhoes-de-eleitores-filiados-apartidos-politicos. Acesso em: 06/02/13.

WEAVER, David H.; VILLNAT, Lars. The global journalists in the 21st century. New York: Routledge, 2012, p 365-381.

Este artigo e todo o conteúdo da Estudos em Jornalismo e Mídia estão disponíveis em http://www.periodicos.ufsc.br/index.php/jornalismo/index 